\title{
A EDUCAÇÃO FÍSICA NO PLANO DA EXPERIÊNCIA: IMPLICAÇÕES NA PESQUISA E NA INTERVENÇÃO PROFISSONAL E DOCENTE
}

\author{
Flávio Soares Alves \\ Universidade do Estado de São Paulo, Rio Claro, São Paulo, São Paulo, Brasil. \\ Yara Maria de Carvalho \\ Universidade de São Paulo, São paulo, São Paulo, São Paulo, Brasil.
}

\begin{abstract}
Resumo:A pesquisa no plano da experiência é, certamente, uma prática investigativa estranha à Educação Física haja vista a evidente afinidade da área com as metodologias científicas tradicionais pautadas pela visão positiva de ciência. Não obstante, a ousadia de ancorar a visibilidade da pesquisa e da intervenção no plano da experiência garante a possibilidade de experimentar outras ciências na Educação Física. Para tanto é preciso apostar em uma reversão metodológica que se move no jogo entre pesquisador e sujeito. Como ancorar a visibilidade da pesquisa e da intervenção em meio a este jogo? O princípio da cartografia oferece pistas, através das quais, mobilizamos esta questão.
\end{abstract}

Palavras-chave: Educação Física. Plano da Experiência. Pesquisa. Intervenção.

\section{Introdução}

A pesquisa em Educação Física nos lembra, muitas vezes, da sua afinidade histórica com as metodologias científicas tradicionais que impõem o enquadramento do exercício investigativo à medida que distingue e opõe o pesquisador e objeto de pesquisa como prerrogativa à produção do conhecimento. Nesse modelo, o pesquisador aprende sobre como aplicar um método e operacionalizar conceitos segundo procedimentos preestabelecidos que regulam o exercício investigativo segundo uma ordem devida e, portanto, cientificamente legitimada.

Face à hegemonia desta prática de produção de conhecimento na Educação Física, perguntamos: é possível fazer pesquisa a partir de outro modo de entendimento e relação entre sujeito e objeto de pesquisa? A questão não é recente e reafirma uma necessidade, cada vez mais fulgente no âmbito de estudos da Educação Física, de se fazer pesquisa (e de intervir) atentos às intensidades que se passam, na relação, isto é, no plano da experiência.

Situamos a noção de plano da experiência neste artigo a partir da leitura de Deleuze e Parnet. Segundo estes autores, a experiência é o espaço-tempo onde se registram acontecimentos enquanto "devires ou processos" (DELEUZE e PARNET, 2004, p. 115). Nestes termos, na consistência do real, isto é, na experiência, evidenciam-se as relações, lá no momento mesmo em que acontecem, com toda intensidade de forças que suportam. ${ }^{35}$

\footnotetext{
35 A leitura de Foucault sobre a noção de acontecimento ajuda a compor esta ideia. Para este autor, o acontecimento se efetiva no âmbito da materialidade e encontra seu lugar e consistência na relação, onde entram em cena as intensidades, ou, como diria Niezsche, as potências que movem e atravessam os relacionamentos, dramatizando-os (FOUCAULT, 1996, p. 57; NIETZSCHE, 2008, pp. 288-294). É no campo onde estes relacionamentos acontecem que o plano da experiência se instala.
} 
Em meio ao plano da experiência, não cabe pensar o exercício investigativo seguindo rumos preestabelecidos, forçando o pesquisador a apostar em uma reversão metodológica: ao invés da instituição de um metá-hodós, inscreve-se um hodós-metá, ou seja, a busca por uma meta dá lugar ao "primado do caminhar que traça, no percurso, suas metas" (PASSOS et al., 2009, p. 17). E, nesta reversão, a aplicação de um método daria lugar a uma experiência inventiva forjada entre as relações tramadas ao longo do processo investigativo.

\section{Uma aposta na experiência contra a suposta neutralidade do conhecimento}

Convém salientar, deste já, que estamos cientes de uma suposta injunção logo de início instalada: ao falar sobre a possibilidade de uma reversão metodológica sem se ancorar em uma experiência de fato que nos chame à pesquisa, firmamos um compromisso analítico contrário ao próprio movimento da reversão. No entanto, o suposto "dizer sobre" aqui constituído não busca pelo registro dos procedimentos regulares que firmam à priori as regras de aparecimento do exercício investigativo, pois se assim fosse, constituiríamos o traço de um metá-hódos, quando o que queremos é observar o seu inverso, ou seja, a pesquisa (e a intervenção) que vai caminhando e se calibrando no próprio percurso de seu caminhar. Sendo assim, a escrita aqui constituída não traz regras, mas pistas que apontam para as direções moventes e imprevisíveis da investigação.

A noção de pista é aqui suscitada segundo a compreensão de Passos, Kastrup e Escóssia no livro "Pistas do Método da Cartografia: pesquisa-intervenção e produção de subjetividade" (2009). Segundo estes autores, pistas são referencias "que concorrem para manutenção de uma atitude de abertura ao que vai se produzindo e de calibragem do caminhar no próprio percurso da pesquisa - o hódos metá da pesquisa." (2009, p. 13).

Desta forma, ao situar algumas pistas, este texto abre um campo de discussões sobre a reversão metodológica que ajuda a coletivizar este exercício investigativo no âmbito de estudos da Educação Física.

Cientes das proposições deste artigo é bem provável que o leitor perceba uma sensação de estranhamento e de resistência ao movimento que se desenha. Isto acontece, pois tal reversão aposta em outra disposição da observação junto à realidade estudada, desestabilizando, não raras vezes, a cômoda passividade da suposta neutralidade do pesquisador. Assim, desacomodado, ao invés de instalar a observação sobre o sujeito, numa projeção descendente que o toma de assalto, a reversão metodológica ousa inverter seu ângulo de divergência, dissolvendo o ponto de vista do observador - aquele supostamente neutro que sobrevoa o campo investigativo - para se ancorar na experiência da pesquisa, onde pesquisador e sujeito, juntos, implicam-se e investigam-se no movimento de ancoramento. ${ }^{36}$

Como entender o exercício da pesquisa nestes termos? Está no princípio da cartografia desenvolvido por Deleuze e Guattari (1995a) o desdobramento desta questão.

\section{O exercício cartográfico}

No volume primeiro da obra Mil Platôs (1995), Gilles Deleuze e Félix Guattari apresentam o princípio da cartografia. Segundo os autores, a cartografia surge como um

\footnotetext{
36 O termo "ancoramento" diz respeito ao movimento de implicação do pesquisador junto à realidade que estuda. O pesquisador insiste (se ancora) na experiência, pois faz pesquisa deste ponto de ancoramento.
} 
princípio "inteiramente voltado para uma experimentação ancorada no real" (p.22). O exercício metodológico, assim, não se acomoda nem lá, no âmbito do conhecimento que desemboca nas fórmulas preestabelecidas, nem cá, na contingência sempre eventual dos acontecimentos. O movimento cartográfico se desenha entre o conhecer e o fazer, entre a teoria e a prática, entre o sujeito e o objeto, entre o próprio exercício de pesquisar e o de intervir junto à realidade estudada (PASSOS et al., 2009).

Nesse processo, a pesquisa assume um caráter rizomático. Segundo Deleuze, o pensamento do tipo rizoma "não tem começo nem fim, mas sempre um meio pelo qual ele cresce e transborda" (DELEUZE e GUATTARI, 1995, p. 32). E o meio

não é uma média; ao contrário, é o lugar onde as coisas adquirem velocidade. 'Entre' as coisas não designa uma correlação localizável que vai de uma para a outra e reciprocamente, mas uma direção perpendicular, um movimento transversal que as carrega uma e outra, riacho sem início nem fim, que rói suas duas margens e adquire velocidade no meio (DELEUZE e GUATTARI, 1995, p. 37).

Já a raiz, abre caminho para um pensamento que cresce como uma árvore - modelo arborescente. Sob esta perspectiva o pensamento vai do geral para o particular, do princípio à consequência, na busca por uma fundamentação que ancore este pensamento em um solo de verdade (DELEUZE e GUATTARI, 1995).

O pensamento do tipo rizoma, próprio da cartografia, nos diz do primado da experimentação sobre a ordem prévia da aplicação do método. Decidir-se por este exercício de pesquisa implica em assumir pelo menos três consequências: 1) "pensar não é representar", portanto, a pesquisa não busca uma adequação a uma suposta realidade objetiva; 2) "não há começo real senão no meio", ou seja, não se busca a origem, mas se mapeia os movimentos do devir ${ }^{37}$; 3) e, todo encontro é possível, desde que se amenizem as pretensões por uma verdade a descobrir e se dê acesso a um tateamento cego e sem apoio, que não tenha outras prerrogativas senão aquelas fincadas no cerne da experimentação (ZOURABICHVILI, 2009, p. 53).

Segundo Kastrup, a cartografia "assume uma perspectiva construtivista do conhecimento, evitando tanto o objetivismo quanto o subjetivismo" (PASSOS et al., 2009, p. 49). Desse modo, o conhecimento produzido não se enquadra como representação, tampouco resulta de um ponto de vista subjetivo e relativista: o conhecimento surge como composição. Entretanto, exige experimentar a dissolução, do ponto de vista do observador. ${ }^{38}$

Na obra Diálogos, Deleuze reflete sobre o devir nos seguintes termos: "Devir é nunca imitar, nem fazer como, nem se conformar a um modelo, seja de justiça ou de verdade. Não há um termo do qual se parta, nem um ao qual se chegue ou ao qual se deva chegar. Tampouco dois termos intercambiantes. [...] Os devires não são fenômenos de imitação, nem de assimilação, mas de dupla captura, de evolução não paralela, de núpcias entre dois reinos" (DELEUZE e PARNET, 2004, p. 12).

38 Estamos cientes do quão pode ser perturbador e inquietante este diálogo sobre cartografia. A busca por uma descrição que esclareça devidamente o assunto move o esforço da leitura, todavia a compreensão não se completa, o que a torna insuficiente para aqueles que procuram por objetividade conceitual. Para eles, é preciso pontuar, primeiramente, que não é objetivo deste artigo esgotar a discussão sobre cartografia. Pretende-se apenas desenvolver uma abordagem introdutória e essa opção também tem limites. Tais limites, no entanto, antes de reclamar por mais conceitos que desdobrem, por redundância, uma maior compreensão sobre a cartografia reclamam por uma atitude de abertura do leitor no que tange à busca de referenciais que só ele pode observar ao encontrar em suas próprias experiências caminhos de mobilização do conceito. Assim, o texto que aqui se desenha reclama pelo "fora texto", que não se enquadra na ordem conceitual justamente porque diz respeito ao esforço do leitor na mobilização de seu pensamento frente à estranha (e sempre insuficiente) leitura que realiza. 


\section{Por uma coemergência no olhar investigativo}

Ao assumir uma dissolução, do ponto de vista do observador, a pesquisa - como espaço de intervenção, onde pesquisador e sujeito se implicam - se abre aos diversos pontos de vista que habitam uma mesma experiência de realidade. Nesta abertura, o pesquisador não se deixa dominar, mas também não abandona nenhum ponto de vista. Tal atitude determina um deslocamento, no qual a observação passa a apostar em uma coemergência do olhar entre pesquisador, sujeito e realidade estudada.

A ilusão da independência de um ponto de vista, a partir do qual se pode conhecer sem intervir na realidade, é uma prerrogativa das metodologias científicas tradicionais: parte-se do princípio de que há uma verdade a ser revelada sobre o objeto/sujeito da análise. E é a relação assimétrica entre pesquisador e pesquisado que sustenta esse fundamento, sem o qual não se processa a pesquisa.

O pesquisador movido por esta prerrogativa cerca-se, o tempo todo, de cuidados para controlar sua intervenção junto ao campo da pesquisa com vistas a garantir uma suposta neutralidade do conhecimento produzido à luz de uma objetividade que possibilita a determinação de uma verdade devidamente legítima sobre o objeto aos olhos da ciência (PASSOS et al, 2009).

Todavia, em última análise, se há uma verdade a ser revelada, não é o pesquisador o produtor e editor (devidamente ratificado pela ciência) de um conhecimento sobre o objeto de pesquisa? Se assim é, não há nesta produção e edição uma intervenção (mesmo que minimizada e insistentemente negada)?

A questão é polêmica. Segundo Lourau (1993) o ideal de inteligibilidade mantém os limites restritos do campo científico, ao sustentar a suposta neutralidade e objetividade do pesquisador na produção do conhecimento científico. E, segundo Passos e Eirado, a neutralidade e a objetividade do conhecimento são garantidas:

pela distância mantida entre aquele que conhece e aquilo que deve ser conhecido. Sujeito e objeto se distinguem e se separam, constituindo-se uma política cognitivista assentada na perspectiva de terceira pessoa do conhecimento: conheço à distância, conheço porque me distancio. (PASSOS et al, 2009, p. 115).

Nestes termos, a neutralidade do conhecimento na condução da pesquisa é o que garante, para aqueles que acreditam nela, a definição de uma conclusão lógica sobre o objeto pesquisado. Assumem, assim, a instituição de uma fórmula geral, ${ }^{39}$ que se coloca sobre a experiência pesquisada, representando-a. Depois de forjada, essa fórmula geral se transmuta em conhecimento, a priori, e, como tal, se firma para além da experiência, como irrecusável (NIETZSCHE, 2008, pp. 268-271).

$39 \quad$ Na leitura de Nietzsche sobre Kant, o entendimento que corre a priori é um conhecimento puro, e como tal, não é absolutamente um conhecimento, mas um artigo de fé regulador (NIETZSCHE, 2008). É este conhecimento a priori que estamos chamando de "fórmula geral": só se conforma o real nos termos da lógica e da razão, quando se submete este real a uma "fórmula geral". Não há valor de verdade nesta "fórmula geral", mas antes "um imperativo sobre aquilo que deve valer como verdadeiro" (NIETZSCHE, 2008, p. 271). 
A ideia do exercício investigativo como um exercício de aplicação metodológica encontra seu suporte aqui, enquanto fórmula geral, haja vista os procedimentos metodoló gicos previamente estabelecidos estarem certificados por longa tradição acadêmico-científica. A experiência se converte em teste! Este tipo de metodologia submete o plano da experiência a um ideal de inteligibilidade guiado por pressupostos objetivistas e cientificistas que só se instalam na investigação quando o pesquisador assume a cômoda posição da neutralidade na observação (PASSOS, et al, 2009).

Guattari (2004) irá se dedicar a uma severa crítica a este ideal de inteligibilidade ao apostar na noção de transversalidade. O plano da transversalidade expressa uma dimensão da realidade que experimenta o cruzamento das várias forças que a compõem. O que é produzido nessa experiência concreta de comunicações transversais inaugura um plano de flutuações da experiência que possibilita a habitação de vários pontos de vista em sua emergência, sem firmar identificação e apego.

A prática de pesquisa que se experimenta nesta rede de comunicações transversais é também, e ao mesmo tempo, atravessada pelas múltiplas vozes que perpassam a rede. Como efeito, a produção de conhecimento torna-se inseparável da produção da realidade (GUATTARI, 2004).

Ora, se não existe neutralidade na produção do conhecimento, como advoga Guattari, deve-se entender que as subjetividades e o plano pessoal invadem irremediavelmente o campo da pesquisa?

Recorremos a experiência da escrita para nos ajudar a pensar essa questão à medida que a escrita inscreve-se no processo de produção de conhecimento e, segundo Lourau, promove a dissolução do humano. ${ }^{40} \mathrm{E}$ nesta experiência de dissolução, a escrita comporta variações de velocidade que permitem a abertura a uma narrativa operada em uma espécie de transe (LOURAU 1998).

Lourau (1998) chama este exercício narrativo mobilizado pela dissolução do humano de escrita automática. Esta escrita tira do texto o excesso de pessoalidade, permitindo que o autor possa compor o sentido nos domínios de um plano coletivo, onde experimenta o limite da consciência de si e, deste ponto, já não consegue se perceber nem fora nem dentro da realidade estudada.

Neste sentido, a pesquisa cartográfica se reconhece como pesquisa-intervenção, pois não escreve sobre o outro. Não há condução do outro na escrita cartográfica. O pesquisador não leva o sujeito em suas mãos, direcionando-o à luz de suas intenções, mas acompanha um processo que ele não conhece de antemão, tateando-o às cegas à medida que se joga no plano da experiência. Na intervenção, portanto, o pesquisador habita a experiência sem apego a um ponto de vista e, a cada passo, busca dissolver os pontos de vista que lhe acometem, sem anular a observação.

Convém salientar, não podemos confundir dissolução de ponto de vista do observador com anulação da observação. A dissolução do ponto de vista implica na desmontagem dos juízos de valor e da vigência insistente, linear e monótona da consciência. A solvência destes juízos eleva a intervenção para um plano coletivo, onde, como diria Guattari (2004), transita uma rede de comunicações transversais que atravessam o pesquisador em seu ato investigativo, atando produção de conhecimento e produção de realidade. Entre conhecer e

40 A dissolução do humano abranda as pretensões coercivas da identidade, inscritas no plano pessoal, permitindo um acolhimento do outro e as variações da experiência (LOURAU 1998). 
fazer e entre teoria e prática, o cartógrafo ${ }^{41}$ se ancora na experiência. Para tanto, como advoga Passos e Eirado,

não pode estar localizado na posição de observador distante, nem pode localizar seu objeto como coisa idêntica a si mesma. O cartógrafo lança-se na experiência, não estando imune a ela. Acompanha os processos de emergência, cuidando do que advém. É pela dissolvência do ponto de vista que ele guia sua ação. (PASSOS et al, 2009, p. 129).

Assim, atento a uma dissolvência de si, o cartógrafo mergulha no território que se propõe estudar e se encharca dos elementos que nele consistem.

\section{Outra posição política sobre o conhecimento}

A dissolução do ponto de vista do observador impõe uma narrativa à pesquisa que difere daquela, nem sempre assumida, na pesquisa pautada na relação de oposição entre pesquisador e objeto. Com esta alteração na narrativa, a política da pesquisa também se altera.

Que diferença política é esta? Primeiramente, é preciso demarcar, tal como salienta Passos e Barros, que toda produção de conhecimento “... se dá a partir de uma tomada de posição que nos implica politicamente.” (PASSOS et al, 2009, p. 150). Quando a pesquisa aposta nos pressupostos de um modelo de representação, o pesquisador assume que tem algo a dizer sobre o objeto pesquisado. Assim, firma-se uma política de pesquisa atenta a um mundo dado a conhecer, no qual o pesquisador forja a produção do conhecimento à luz da consciência - faculdade racional, na qual se engendra a objetividade científica (PASSOS et al, 2009).

Distintamente, quando a pesquisador ousa romper com a oposição, a produção de conhecimento não é concebida sem um exercício de experimentação que ata, no mesmo plano, pesquisador e objeto. Imerso neste plano da experiência, a observação já não é mais autoral, mas coletiva. Inscreve-se aí outra posição política de produção do conhecimento.

Enquanto no primeiro caso a produção de conhecimento firma compromisso com um rigor de natureza asséptica que separa o fazer e o dizer, como recurso através do qual se edifica a verificação científica, no segundo caso, não há verificação sem intervenção, não há rigor sem interesse, sem mergulho na experiência. ${ }^{42}$

O mergulho implica assumir, por exemplo, que durante o trajeto podemos nos perder, mas trata-se de um perder-se que mobiliza outros movimentos que acontecem não como resultado de uma escolha individual - que firma a todo custo a distinção entre pesquisador e objeto -, mas de uma sensibilidade às forças processuais em curso na investigação.

$41 \quad$ O cartógrafo é o pesquisador que pauta seu exercício investigativo a partir dos rumos do porvir desencadeados pelo princípio da cartografia, desenvolvido por Deleuze e Guattari (PASSOS et al, 2009).

42 Varela (1995) ensina esta lição ao cartógrafo: a experiência concerne à emergência de mudanças. Aquilo que já está aí como dado inelutável - no plano das formas - não concerne à experiência e só existe na perspectiva de um observador que se esforça para teorizar sobre o que acontece na emergência da experiência. Como desdobramento desta perspectiva teórica, a realidade aparece como dada, em função de um ponto de vista que recorta a experiência de seu plano de emergência. Todavia, o conhecer não é tão somente um exercício de representação, no qual há um recorte temporal do objeto de seu plano concreto de produção. O conhecer para o cartógrafo só se constitui de fato quando o pesquisador se engaja no mundo a ser conhecido. O direcionamento deste ato de conhecer é prospectivo, pois está adiante: a curiosidade desbrava-lhe os rumos. 
Há uma injunção aqui, ou não? Afinal, quando se fala em aplicação do método, nem de longe o pesquisador deseja e pode se reconhecer perdido no curso da pesquisa. As regras de definição do objeto, sob a trilha da evidência, não deixam margem às dúvidas. E se não há dúvidas, não se dá chance e, sobretudo, valor aos elementos que desviam o olhar do pesquisador da trilha da evidência. Não obstante, não se trata aqui de uma injunção, mas de outros modos de se fazer pesquisa, nos quais o que está em jogo é a composição daquilo que insiste como força de criação no fenômeno estudado.

Como proceder esta composição no âmbito da escrita da pesquisa? O discurso irônico dos estudos de Nietzsche e Foucault inspira possibilidades de resposta a esta questão. Aquele que narra com ironia - aponta Albuquerque Júnior, intérprete de Nietzsche e Foucault:

sabe que o que diz não é propriamente o que a coisa é e sabe que a coisa nunca é aquilo de que dela se diz. As palavras nunca dão conta de revelar a verdade das coisas e estas sempre estão em excesso em relação àqueles conceitos que as pretende definir. (RAGO; VEIGA-NETO, 2008, p. 100).

Neste sentido, o irônico não vai de encontro com a verdade, mas desmonta as supostas versões verdadeiras que encontra pelo caminho, mostrando que elas não passam de fabricações históricas tecidas por olhares crentes e dogmáticos que anseiam pelo brilho eterno no pilar das verdades ditas.

O irônico, assim, tece sua narrativa longe da acomodação de um lugar. A sedução de uma verdade, a saber, facilmente o localiza e o faz sucumbir a seus domínios. Afinal, a busca da verdade é uma tarefa sedutora, já dizia Nietzsche, ter uma verdade a ser dita é sinal de poder. O irônico, no entanto, acometido por uma curiosidade mobilizante, ousa esnobar desta modalidade de poder e lhe dá as costas, na busca de um não-lugar que o distancia da norma, da ordem e dos lugares estabelecidos e valorizados positivamente. Na não-localidade faz a experiência da escrita: uma escrita que já não é mais sua, porque é tecida na fronteira, nos limites de um si fora de si. ${ }^{43}$

Antes de iniciar a leitura do próximo e último item deste artigo, convém pontuar que o diálogo entre os estudos aqui apresentados de modo algum buscam por uma fundamentação teórica da pesquisa cartográfica no âmbito da Educação Física, pois não há busca por fundamentação do conhecimento na cartografia, portanto não há aqui um esforço que justifique a aproximação entre cartografia e Educação Física. Apostar no exercício da cartografia implica em assumir uma prática de composição da realidade estudada, uma composição que está sempre fadada a ultrapassagem, a cada vez que o pesquisador se lança à pesquisa e a intervenção. Desta forma, a busca pela literatura e pelos conhecimentos teóricos funciona dentro de outra lógica reflexiva, onde, ao invés do fundamento, se instala o sem fundo. ${ }^{44}$ A escritura em abismo abriga um pensamento que só se constitui em cena e como tal, está sempre 'por fazer'. Realça-se assim, a figura de um escritor em movimento, que se insinua na textualidade - na ordem estabelecida pelo discurso - e nela se faz ausente, abandonando-a “... absolutamente às vicissitudes de um pensar que não precede, mas que é concomitante ao ato da escritura." E, desse modo, a escritura vai constituindo um dizer que, “... sem preestabelecer o que há a ser dito, deixa aparecer um saber sem sujeito" (RAGO; VEIGA-NETO, 2008,

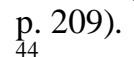

Segundo Deleuze, o fundamento age no âmago da representação para determiná-la, assim, o fundamento determina as possibilidades de investigação, à luz da representação. O sem-fundo, por sua vez foge 
Assim, resta à reflexão a prática da gravitação, ${ }^{45}$ onde os estudos e as teorias giram ao redor deste ponto de "a-fundamento", tornando possível o exercício da escrita: uma escrita que não se coloca sobre o material empírico forjado na investigação, mas que compõe com ele, como exercício lúdico de invenção da pesquisa no campo da escrita.

\section{Por que cartografar na Educação Física?}

A pesquisa imersa no plano da experiência é, certamente, uma prática investigativa estranha à Educação Física haja vista a evidente afinidade da área com as metodologias científicas tradicionais pautadas pela visão positiva de ciência.

A intervenção profissional endossa o peso desta afinidade quando se preocupa muito mais com as regularidades e prescrições que mediam a relação profissional-sujeito, do que com os processos que movem esta relação para além desta restrita visão pedagógica e didática que suporta e que reconhece como devida.

Esta tendência na intervenção afeta diretamente a produção de conhecimento gerada na prática de pesquisa pois, preocupado com as regularidades, o pesquisador irá direcionar sua atenção na objetividade como qualidade da produção de conhecimento e da intervenção. Evidencia-se aí, a visão e a ação tecnicista na produção de conhecimento e na atuação profissional e docente.

A visão tecnicista se instala como exigência objetiva na busca de uma evidência, ou melhor, de uma exatidão sobre o objeto verificado (no caso do pesquisador) e sobre a intervenção proposta (no caso da atuação profissional e docente). E esta instalação está fortemente fixada nos conceitos e nas representações justamente para não se escapar dela. Em função desta perspectiva imperativa, que de tão corrente tornou-se quase natural, o foco do olhar é orientado mediante uma realidade forjada na objetividade, pois, sem ela, não é possível sistematizar um conhecimento e tampouco aplica-lo na prática profissional e docente.

A visão tecnicista, no entanto, não alcança os movimentos que escapam deste quadro objetivo e sistêmico que descerra. Para observar estes movimentos que sobrepõem à visão tecnicista é preciso desinstalar este olhar devido para permitir o acesso a outra dimensão de entendimento, aquela que agrega às exigências tecnicistas (às objetividades) os movimentos que forçam a sua transgressão, segundo as relações traçadas no plano da experiência. Tal visão se localiza no "espaço entre", como visibilidade implicada, lá no momento mesmo em que a intervenção/pesquisa acontece.

É justamente aí que pontuamos a importância e a pertinência do exercício cartográfico, como prática que torna possível o mapeamento desta visibilidade implicada, entre a objetividade e as subjetividades. Cabe ressaltar que a cartografia não descarta a visão

da representação, forçando o pensamento a pensar ao redor deste ponto de a-fundamento (2006, pp. 377-382). É importante frisar que a noção de representação aqui suscitada remete ao exercício propositivo da consciência na designação e fundamentação das coisas. Tal designação e fundamentação apreendem e condensam as coisas, modelando-as segundo um jogo hipotético e categórico que torna possível sua determinação à luz dos conhecimentos teóricos (mathésis) (DELEUZE, 2006).

$45 \quad$ A prática da gravitação implica em dar voz ao jogo eventual e intensivo que se instala na experiência investigativa: o jogo entre pesquisador e sujeitos, estudos e relações, intenções e devires. A gravitação faz ressoar um encontro essencial afinado não com os movimentos da fundamentação - que tudo quer dobrar sob os contornos restritivos que impõe - mas com a disparidade. Chamamos disparidade "esse estado da diferença infinitamente desdobrada, ressoando indefinidamente" (DELEUZE, 2006, p. 314), no qual a escrita surge como extensão que só existe dentro deste campo gravitacional movimentado. 
tecnicista, mas a dissolve em um plano de composição, pois, na prática, a visão tecnicista sofre remanejamentos - transgressões - que forçam certa invenção da intervenção/pesquisa, segundo as demandas em processo no plano da experiência.

A pesquisa e a intervenção geradas pelo exercício cartográfico não se arriscam na edificação de um discurso protocolar que os regulamente, mas chamam a atenção para a singularidade dos processos, onde a ordem de natureza protocolar - observada pelo olhar tecnicista - é posto à prova nas circunstâncias moventes nas quais se envolve.

Desta forma, o exercício cartográfico se recusa a prescindir do real, ancorando-se na experiência para traçar daí, desta visibilidade implicada, os rumos da pesquisa e da intervenção. O exercício de pesquisa, assim, em Educação Física, se desvia do compromisso de buscar uma suposta exatidão que firmaria à priori as bases do conhecimento e da intervenção, para garantir um compromisso ético com a realidade estudada.

O exercício cartográfico ensina que toda aplicação regulamentar está fadada à reinvenção quando nos abrimos às intensidades que atravessam o plano da experiência. Não estar atento a estes atravessamentos significa retroceder ao compromisso com uma visão estatutária que se serve da autoridade a ela outorgada pela ciência, para restaurar a assimetria e a oposição entre pesquisador e pesquisado, profissional e sujeito.

Como desdobramento desta discussão, ou provocação, é possível considerar também que ao deslocar a atenção e a ação para o plano da experiência, a cartografia dissolve a distinção entre pesquisa e intervenção. O docente, por exemplo, é um pesquisador em potencial, pois pode se servir de sua própria prática de intervenção para movimentar a pesquisa em Educação Física, mapeando sua atuação atento às relações constituídas junto a seus alunos.

Uma possibilidade de encaminhar este mapeamento seria observar como os planejamentos propostos deixam-se afetar pelos processos que atravessam a atuação docente. $\mathrm{O}$ exercício investigativo forjado, neste caso, irá acompanhar as transgressões, ou seja, as construções e reconstruções das intencionalidades educativas segundo os movimentos coautorais forjados na atuação implicada.

O desafio aqui lançado é apostar nestas transgressões como potencial material de pesquisa, na trilha destas irregularidades mapeadas. Tais irregularidades vazam a ordem sistêmica e objetiva que controla os encaminhamentos da pesquisa e da intervenção, alertando-nos de que nem tudo é dado a conhecer, mas, antes, a se experimentar, forjar e reinventar.

Resta a coragem e a ousadia de ancorar-se na pista das irregularidades e fazer da prática investigativa um modo de experimentar e produzir outras ciências na Educação Física.

\section{PHYSICAL EDUCATION IN THE PLAN OF EXPERIENCE: IMPLICATIONS FOR RESEARCH AND FOR PROFESSIONAL AND TEACHING INTERVENTION}

Abstract: The research in the plan of experience is certainly a strange investigative practice to Physical Education given the apparent affinity of the area with the traditional scientific methodologies guided by positive view of science. However, the boldness to anchor the research and intervention visibilities in the plan of experience ensure the possibility to produce other sciences in Physical Education. Therefore it is necessary to bet on a methodological reversion that happen in the game between researcher and subject. How anchor the research and intervention visibilities among this game? The principle of cartography gives tracks that help us mobilize this question.

Key-words: Physical Education. Plan of experience. Research. Intervention. 


\section{EDUCACIÓN FÍSICA EN EL PLAN DE LA EXPERIENCIA: IMPLICACIONES PARA LA INVESTIGACIÓN Y PARA LA INTERVENCIÓN PROFESIONAL Y DOCENTE}

Resumen:La investigación en el plan de la experiencia es sin duda una extraña práctica investigativa a la Educación Física, dada la afinidad aparente del área con las metodologías científicas tradicionales guiadas per la visión positiva de la ciencia. Sin embargo, la audacia de anclar la visibilidad de la investigación y de la intervención en el plan de la experiencia asegura la posibilidad producir otras ciencias en Educación Física. Por lo tanto es necesario apostar en una reversión metodológica que ocurren en el juego entre el investigador y el sujeto. Cómo anclar la visibilidad de la investigación y de la intervención dentro de este juego? El principio de la cartografía da pistas que nos ayudan a movilizar a esta pregunta.

Palabras clave: Educación Física. Plan de la experiencia. Investigación. Intervención.

\section{Referências}

ALBUQUERQUE JÚNIOR, D. M.; VEIGA-NETO, A.; SOUZA FILHO, A. Cartografias de Foucault. Belo Horizonte: Autêntica, 2008.

DELEUZE, G. Diferença e repetição. Rio de Janeiro: Graal, 2006.

DELEUZE, G.; GUATTARI, F. Mil Platôs: capitalismo e esquizofrenia. Vol.1. São Paulo: Ed. 34, 1995.

DELEUZE, G.; PARNET, C. Diálogos. Trad. Eloísa Araújo Ribeiro. São Paulo: Escuta, 1998.

FOUCAULT, M. A ordem do discurso. São Paulo: Loyola, 1996.

GUATTARI, F. A transversalidade. In. Psicanálise e transversalidade: ensaios de análise institucional. Aparecida - SP: Ideias e Letras, 2004, p. 75-84.

LOURAU, R. Análise institucional práticas de pesquisa. Rio de Janeiro: UERJ, 1993.

A análise institucional. Petrópolis: Vozes, 1996.

L'écriture automatique. Les Cahiers de I'implication. In: Revue d'analyse

Institutionnelle. n. 2, 1998, p. 35-38.

NIETZSCHE, F. A gaia ciência. São Paulo: Companhia das Letras, 2001. A vontade de poder. Rio de Janeiro: Contraponto, 2008.

PASSOS, E.; KASTRUP, V.; ESCÓSSIA, L. (Orgs.) Pistas do método da Cartografia: pesquisa-intervenção e produção de subjetividade. Porto Alegre: Sulina, 2009.

RAGO, M.; VEIGA-NETO, A. (Orgs.) Figuras de Foucault. Belo Horizonte: Autêntica, 2008. 
SOUZA, P. O sujeito fora de si: movimentos hídridos de subjetivação na escrita foucaultiana. In: RAGO, M.; VEIGA-NETO, A. (Org.) Figuras de Foucault. Belo Horizonte: Autêntica, 2008, pp. 205-214.

VARELA, F. Sobre a competência ética. Lisboa: Edições 70, 1995.

VERMERSH, P. L'entretien d'explicitation. Saint-Denis, Issy-les-Molineaux: ESF, 2000.

ZOURABICHVILI, F. O Vocabulário de Deleuze. Rio de Janeiro: Relume Dumará, 2009

Recebido em: 11/03/2014

Revisado em: 16/10/2014

Aprovado em: 09/03/2015

Endereço para correspondência:

flavio_alves@rc.unesp.br

Flávio Soares Alves

Universidade Estadual Paulista - IB - Depto. EF - Campus de Rio Claro.

UNESP - Universidade do Estado de São Paulo

Jardim Bela Vista

13506900 - Rio Claro, SP - Brasil 